\title{
Are childhood and adult ADHD the same entities?
}

\author{
Alan Apter ${ }^{1,2}$ \\ Published online: 5 June 2018 \\ c) Springer-Verlag GmbH Germany, part of Springer Nature 2018
}

There is a widespread prevailing assumption that attention deficit hyperactivity disorder (ADHD) is a neurodevelopmental disorder with a child onset that persists on through adulthood and is more common in males. For example, a meta-analysis found that severity of childhood ADHD, treatment for childhood ADHD comorbid conduct disorder and comorbid major depressive disorder were predictive of adult ADHD (Caye et al. [1], [2]). Recently, Moffit et al. [3] reported results from the well-known Dunedin study that casts doubts on this axiom. They reported a childhood prevalence of ADHD of $6 \%$ with male predominance, comorbid psychiatric disorders, neurocognitive deficits, polygenic risk and adult impairments. They also reported an adult prevalence of $3 \%$ associated with substance dependence and the need for psychiatric treatment. All these results were in accordance with prevailing views of this disorder.

What was totally unexpected was that the childhood ADHD group and the adult ADHD group "comprised virtually non-overlapping sets; $90 \%$ of adult ADHD cases lacked a history of childhood ADHD. Also unexpectedly, the adult ADHD group did not show tested neuropsychological deficits in childhood or adulthood, nor did they show polygenic risk for childhood ADHD". The authors concluded that adult ADHD might not be a childhood-onset neurodevelopmental disorder; a conclusion which if supported by additional evidence would revolutionize our understanding of the ADHD concept.

In an accompanying editorial to the Moffitt et al. article led by a quote from the Firesign Theatre, "Everything you know is wrong", Castellanos [4] quotes additional evidence from the New York Longitudinal Study, where brain structure differences (decreased grey matter/cortex) in adulthood were more reflective of childhood diagnosis than of adult

Alan Apter

eapter@clalit.org.il

1 Schneider Children's Medical Centre of Israel, 14 Kaplan Street, PO Box 559, 4920235 Petach Tikvah, Israel

2 Ruppin Academic Center, Emek Hefer, Israel diagnostic status and implies that adult-onset and child-onset ADHD may well be different entities. This is not readily reconcilable with numerous reports of a familial association of offspring ADHD with parental ADHD or ADHD symptoms (e.g. Wesseldijk et al. [5] epub ahead of print), which have even been extended to the therapeutic level by addressing the treatment of affected mothers (Häge et al. [6] epub ahead of print).

Seen in this context, the article by Sabina Millinet and co-workers in this issue of the journal [7] may have particular relevance. They argue that the Moffit results may be explained by the use of self-reports to characterize attention deficit symptoms. "Although the available literature is limited so far, results from existing studies suggest that selfreports of ADHD symptoms have lower informative value than do parent reports, or rather that parent-reported ADHD symptoms show higher associations with cognitive-neurophysiological correlates compared to self-reported symptoms". There may also be gender differences in the continuity and discontinuity of symptoms of ADHD. They base their arguments on their own longitudinal sample from the Mannheim Study of Children at Risk, an epidemiological cohort study examining the outcome of early risk factors from infancy to adulthood. After the initial examination at age 3 months, subsequent assessments were conducted at regular intervals throughout development. Their study used data from assessments carried out at 4.5, 8, 11, 15, 19, 22, 23 , and 25 years of age. They utilized both parent and subject reports and point out that relying only on self-reports may be misleading. This longitudinal study of ADHD trajectories showed that females with diagnosed childhood ADHD had significantly more self-rated ADHD symptoms at age 15 years than those without a childhood ADHD diagnosis and that this difference persisted in young adulthood. Moreover, in female adults, childhood diagnoses of ADHD (and CD/ODD), but not internalizing disorders significantly predicted self-reported ADHD. In addition, at age 15 years, they found a difference between girls with and without a childhood ADHD diagnosis whose parents rated them as normal: girls with a previous childhood ADHD diagnosis 
reported more ADHD symptoms than did girls without such a diagnosis. There was no comparable effect in girls whose parents still reported significant ADHD symptoms at the age of 15 years. This was not the case for males: None of the predictors significantly predicted self-reported ADHD symptoms at age 25 years in males.

Thus, in males there might well be a support for the Moffit results but not for girls. These gender differences may well be the result of basic biological differences in the development of attention deficit disorder symptoms. However, they may be due to cultural differences in self-reporting of psychopathology between males and females or even between New Zealand and German tolerance of ADHD symptomatology. In any event we should not lose sight of the inherent problems with the descriptive approach to diagnosis used by the DSM to characterize attention deficit disorder. The symptoms whether based on self or even on informant reports may not always be reliable or valid.

The ultimate goal is to develop an objective reliable and biologically based classification of ADHD, a goal which unfortunately remains elusive.

\section{References}

1. Caye A, Spadini AV, Karam RG, Grevet EH, Rovaris DL, Bau $\mathrm{CH}$, Rohde LA, Kieling C (2016) Predictors of persistence of ADHD into adulthood: a systematic review of the literature and meta-analysis. Eur Child Adolesc Psychiatry 25(11):1151-1159

2. van Lieshout M, Luman MT, Wisk JW, van Ewijk H, Groenman AP, Thissen AJ, Faraone SV, Heslenfeld DJ, Hartman CA,
Hoekstra PJ, Franke B, Buitelaar JK, Rommelse NN, Oosterlaan J (2016) A 6-year follow-up of a large European cohort of children with attention-deficit/hyperactivity disorder-combined subtype: outcomes in late adolescence and young adulthood. Eur Child Adolesc Psychiatry 25:1007-1017. https://doi.org/10.1007/s0078 7-016-0820-y

3. Moffitt TE, Houts R, Asherson P, Belsky DW, Corcoran DL, Hammerle M, Harrington H, Hogan S, Meier MH, Polanczyk GV, Poulton R, Ramrakha S, Sugden K, Williams B, Rohde LA, Caspi A (2015) Is adult ADHD a childhood-onset neurodevelopmental disorder? Evidence from a four-decade longitudinal cohort study. Am J Psychiatry 172(10):967-977

4. Castellanos FX (2015) Is adult-onset ADHD a distinct entity? Am J Psychiatry 172(10):929-931

5. Wesseldijk LW, Dieleman GC, van Steensel FJA, Bartels M, Hudziak JJ, Lindauer RJL, Bögels SM, Middeldorp CM (2018) Risk factors for parental psychopathology: a study in families with children or adolescents with psychopathology. Eur Child Adolesc Psychiatry. https://doi.org/10.1007/s00787-018-1156-6 (Epub ahead of print)

6. Häge A, Alm B, Banaschewski T, Becker K, Colla M, Freitag C, Geissler J, von Gontard A, Graf E, Haack-Dees B, Hänig S, Hennighausen K, Hohmann S, Jacob C, Jaite C, Jennen-Steinmetz C, Kappel V, Matthies S, Philipsen A, Poustka L, Retz W, Rösler M, Schneider-Momm K, Sobanski E, Vloet TD, Warnke A, Jans T (2018) Does the efficacy of parent-child training depend on maternal symptom improvement? Results from a randomized controlled trial on children and mothers both affected by attention-deficit/ hyperactivity disorder (ADHD). Eur Child Adolesc Psychiatry. https://doi.org/10.1007/s00787-018-1109-0 (Epub ahead of print)

7. Millenet S, Laucht M, Hohm E et al (2018) Sex-specific trajectories of ADHD symptoms from adolescence to young adulthood. Eur Child Adolesc Psychiatry. https://doi.org/10.1007/s0078 7-018-1129-9 